\title{
LETTER
}

\section{Echinocandins - first line in invasive candidiasis: how strong is this 'strong' evidence?}

\author{
João Gonçalves-Pereira*1,2 and Pedro Póvoa',2 \\ See related research by Kett et al., http://ccforum.com/content/15/5/R253
}

In the previous issue of Critical Care, Kett and colleagues [1] published a post hoc analysis of a randomized controlled trial comparing the efficacy of anidulafungin versus fluconazole in non-neutropenic critically ill patients with invasive Candida infections (89\% had candidemia). But the authors' claim that their data support the superiority of anidulafungin may be misleading and raises several concerns. First, the primary endpoint of the study was clinical and microbiological success at the end of intravenous therapy. However, surrogate endpoints must be predictive of the clinically relevant endpoint that is mortality [2]. That was not the case, and no difference in 28-day mortality was noted (20.2\% versus $24.3 \%$; $P=0.57$ ). Second, in the present study [1], the duration of intravenous therapy was unclear, but in their original study [3], patients on anidulafungin received, on average, 3 more days of intravenous therapy than the fluconazol group. Besides, more patients in the anidulafungin arm had their central venous catheter removed. These facts markedly biased the results and could explain the observed differences [4]. Third, this was a non-inferiority study [3]. Therefore, from a statistical point of view, any conclusions regarding superiority must be interpreted with extreme caution [5]. Finally, at the time of the study design [3], the use of amphotericin $\mathrm{B}$, and not fluconazole, was recommended in unstable patients with invasive Candida infections. Therefore, the choice of fluconazole as a comparator limits the study conclusions even further. We believe that, at present, there is no evidence to support the selection of a specific antifungal class in invasive Candida infections [4].

\section{Authors' response}

Daniel H Kett, Annette C Reboli, Andrew F Shorr and Haran T Schlamm

In response to the letter by Gonçalves-Pereira and Póvoa, we would like to point out that, in our post hoc analysis of seriously ill patients with invasive candidiasis, anidulafungin was more effective than fluconazole in terms of global (combined clinical and microbiological) response at the end of treatment. Recognizing the limitations of our analysis, however, we were unable to conclude that anidulafungin was superior to fluconazole.

Many of the comments of Gonçalves-Pereira and Póvoa were directed at the original study. That study was a prospective, randomized, double-blind phase III trial [3] that incorporated a pre-specified, two-step test for noninferiority and then superiority, an accepted statistical

\footnotetext{
*Correspondence: joaogpster@gmail.com

'Polyvalent Intensive Care Unit, Estrada do Forte do Alto do Duque, Hospital de São Francisco Xavier, Centro Hospitalar de Lisboa Ocidental, 1449-005 Lisboa, Portugal

Full list of author information is available at the end of the article
}

method [6]. The primary endpoint of that study was investigator-assessed global response, a commonly accepted endpoint in candidemia studies. The difference in global response between groups remained significant after adjustment for potential imbalances, including duration of treatment and central line status [3].

We disagree with the claim by Gonçalves-Pereira and Póvoa that previous guidelines did not support the use of fluconazole as a first-line treatment in unstable patients with candidemia. The 2000 guidelines of the Infectious Diseases Society of America (IDSA) recommended either fluconazole or amphotericin as the primary treatment of candidemia regardless of disease severity and noted that fluconazole was used successfully in unstable patients [7]. Fluconazole was specifically chosen as the active comparator in the phase III trial in response to a call for studies comparing echinocandins to fluconazole [8].

The 2009 guidelines of the IDSA recommend an echinocandin as the initial treatment in seriously ill patients [9]. Our data support this recommendation. Recognizing the limitations of our retrospective analysis, 
we called for additional studies in critically ill patients with invasive candidiasis.

\section{Abbreviation}

IDSA, Infectious Diseases Society of America.

\section{Competing interests}

JG-P and PP have each received honoraria from and served as advisor to Gilead (Foster City, CA, USA), Merck Sharp \& Dohme (Whitehouse Station, NJ, USA), and Pfizer Inc (New York, NY, USA).

\section{Authors' contributions}

JG-P and PP both searched the literature, analyzed data, and wrote the manuscript. Both authors read and approved the final manuscript.

\section{Author details}

'Polyvalent Intensive Care Unit, Estrada do Forte do Alto do Duque, Hospital de São Francisco Xavier, Centro Hospitalar de Lisboa Ocidental, 1449-005 Lisboa, Portugal. ${ }^{2}$ CEDOC, Faculty of Medical Sciences, New University of Lisbon, Campo dos Mártires da Pátria, 130, 1169-056 Lisboa, Portugal.

\section{Published: 15 December 2011}

\section{References}

1. Kett DH, Shorr AF, Reboli AC, Reisman AL, Biswas P, Schlamm HT: Anidulafungin compared with fluconazole in severely ill patients with candidemia and other forms of invasive candidiasis: Support for the 2009 IDSA treatment guidelines for candidiasis. Crit Care 2011, 15:R253.
2. DeMets DL: Statistical issues in interpreting clinical trials. J Intern Med 2004, 255:529-537.

3. Reboli AC, Rotstein C, Pappas PG, Chapman SW, Kett DH, Kumar D, Betts R, Wible M, Goldstein BP, Schranz J, Krause DS, Walsh TJ; Anidulafungin Study Group: Anidulafungin versus fluconazole for invasive candidiasis. N Engl J Med 2007, 356:2472-2482.

4. Póvoa P, Gonçalves-Pereira J: Treatment of candidemia in adult patients without neutropenia - an inconvenient truth. Crit Care 2011, 15:114

5. Gotzsche PC: Lessons from and cautions about noninferiority and equivalence randomized trials. JAMA 2006, 295:1172-1174.

6. Wiens BL: Something for nothing in noninferiority/superiority testing: a caution. Drug Inf J 2001, 35:241-245.

7. Rex JH, Walsh TJ, Sobel JD, Filler SG, Pappas PG, Dismukes WE, Edwards JE: Practice guidelines for the treatment of candidiasis. Infectious Diseases Society of America. Clin Infect Dis 2000, 30:662-678.

8. Walsh TJ: Echinocandins - an advance in the primary treatment of invasive candidiasis. N Engl J Med 2002, 347:2070-2072.

9. Pappas PG, Kauffman CA, Andes D, Benjamin DK Jr., Calandra TF, Edwards JE Jr., Filler SG, Fisher JF, Kullberg BJ, Ostrosky-Zeichner L, Reboli AC, Rex JH, Walsh TJ, Sobel JD; Infectious Diseases Society of America: Clinical practice guidelines for the management of candidiasis: 2009 update by the Infectious Diseases Society of America. Clin Infect Dis 2009, 48:503-535.

doi:10.1186/cc10580

Cite this article as: Gonçalves-Pereira and Póvoa: Echinocandins - first line in invasive candidiasis: how strong is this 'strong' evidence? Critical Care 2011, 15:461. 